Talaat A Abdel Aaty ${ }^{1}$, Mohamed M Rezk², Magdy H Megallaa'1D, Maha E Yousseif ${ }^{1}$, Heba S Kassab

${ }^{1}$ Unit of Diabetes and Metabolism, Department of Internal Medicine, Faculty of Medicine, Alexandria University, Alexandria, Egypt

${ }^{2}$ Department of Chemical and Clinical Pathology Faculty of Medicine, Alexandria University, Alexandria, Egypt

\title{
Serum leptin level and microvascular complications in type 2 diabetes
}

\section{ABSTRACT}

Background. Type 2 diabetes (T2DM) and its complications are highly prevalent in Egypt and are considered a major health problem. Insulin resistance arising from visceral obesity is the main pathological mechanism of T2DM. Leptin is an adipokine secreted from visceral adipose tissue and its level is proved to be higher in patients with T2DM, but its association with microvascular complications is not yet well-established, for this aim the present study was conducted.

Methods. This cross-sectional study was conducted among 120 participants with T2DM recruited from the diabetes outpatient clinic of Alexandria Main University Hospital, Alexandria, Egypt. Each participant was subjected to full history taking, complete physical examination and laboratory investigations.

Results. Serum leptin level was significantly positively correlated with diabetes duration, BMI, WC, systolic and diastolic blood pressure, $\mathrm{FPG}, \mathrm{HbA}_{1 \mathrm{c}^{\prime}}$ serum insulin level, HOMA-IR, total cholesterol, triglycerides and LDL-C. Regarding microvascular complications, serum leptin level was highly significantly positively correlated with UACR, peripheral neuropathy and retinopathy $(P<0.001)$ and significantly negatively correlated with e-GFR ( $P=0.003)$.
Address for correspondence:

Heba Sadek Kassab

Unit of Diabetes and Metabolism

Department of Internal Medicine, Faculty of Medicine

Alexandria University, Egypt

17 Champollion Street, El Messallah, Alexandria, Egypt, postcode 21131

Phone: +20 1005536874

e-mail: hebakassab_dm@yahoo.com

Clinical Diabetology 2020, 9, 4, 239-244

DOI: $10.5603 /$ DK.2020.0025

Received: 11.02.2020

Accepted: 09.05.2020
Conclusions. Serum leptin level is significantly correlated with microvascular complications in patients with T2DM in Alexandria, Egypt. (Clin Diabetol 2020; 9; 4: 239-244)

Key words: leptin, type 2 diabetes, microvascular complications

\section{Introduction}

Type 2 diabetes (T2DM) represents $90-95 \%$ of patients with diabetes worldwide [1]. Egypt occupies the $8^{\text {th }}$ ranks regarding the prevalence of diabetes. The estimated prevalence of diabetes in Alexandria, Egypt was $16.8 \%$ in 2018 [2]. The main pathogenic mechanism of T2DM is insulin resistance that results in relative insulin deficiency [1]. Most of patients with T2DM are obese and many studies linked obesity to T2DM [3, 4]. Insulin resistance in muscle and liver results from impaired glucose uptake by adipose tissue [5]. Visceral adipose tissue is metabolically active and secretes substances called adipokines. Adipokines leads to development of insulin resistance by many mechanisms $[6,7]$.

Leptin is one of the adipokines secreted from adipocytes in visceral adipose tissue [8]. It is also detected in gastric mucosa, hepatic stellate cells, placenta, ovaries and mammary gland [9]. Leptin is acting as an adipose-derived endocrine signal by inducing satiety through hypothalamic receptors and enhancing lipid metabolism and energy expenditure [10]. Higher serum leptin levels were detected in patients with diabetes and leptin resistance has been implicated in the pathogenesis of diabetes and insulin resistance [11]. Leptin also has an important inflammatory role responsible for endothelial dysfunction, increased oxidative stress, vascular inflammation and proliferation of vascular smooth muscle cells (VSMC) and resultant intimal hyperplasia [12]. 
Vascular inflammation is the core pathological mechanism of diabetic microvascular complications and there is evidence that adipocytokines play a probable role in vascular inflammation and endothelial dysfunction [13].

A well-established relationship between leptin and insulin resistance, diabetes, obesity, inflammation and metabolic syndrome was proved in previous studies [14-16], but its relation to microvascular complications is still unclear. Moreover, microvascular complications are major health problems in Egypt [17]. This invited us to conduct the present study.

\section{Materials and methods}

This cross-sectional study was conducted among 120 participants with T2DM recruited from patients attending diabetes outpatient clinic of Alexandria Main University Hospital, Alexandria, Egypt who accepted to participate in the research after explaining the research aim.

Inclusion criteria included patients with T2DM and $\mathrm{BMI}>18.5 \mathrm{~kg} / \mathrm{m}^{2}$ while exclusion criteria included ischemic cardiovascular event in previous 3 months, severe liver impairment, recent history of major trauma or surgery, hematological disorders or malignancy, chronic inflammatory or autoimmune diseases, as well as patients with recent history of sever significant infection at study entry.

This work was done in accordance with the Ethical Principles for Medical Research Involving Human Subjects outlined in the Helsinki Declaration in 1975 (revised in 2008). An approval was obtained from ethics committee of Faculty of Medicine, Alexandria University. All participates gave their written informed consent after explaining the nature and the aim of the study.

Participants were subjected to:

- Full medical history included following issues: personal data, detailed analysis of different cardio-metabolic risk factors, hypertension and dyslipidemia, history of macrovascular complications of diabetes (cardiovascular disease, cerebrovascular disease or peripheral arterial disease) and the use of antidiabetic, antihypertensive and antidyslipidemic drugs.

- Complete physical examination including body weight and height, body mass index (BMI) was calculated as body weight $(\mathrm{kg})$ divided by body height squared $\left(\mathrm{m}^{2}\right)$. Waist circumference (WC) was measured at the midpoint between highest point of the iliac crest and lowest point of the costal margin at the end of normal expiration according to the WHO recommendations [18].
- Vital signs including pulse and blood pressure (BP) were measured. Neurological examination was performed and diagnosis of peripheral neuropathy was done based on abnormal results of more than one diagnostic test of the following: vibration perception threshold using a $128-\mathrm{Hz}$ tuning fork, temperature perception, pin-prick, ankle reflex and touch-pressure sensation (10-g Semmes-Weinstein monofilament) [19].

- Fundus examination was done in ophthalmology outpatient clinic of Alexandria Main University Hospital using slit lamp biomicroscope plus fundus lens by expert ophthalmologist. Diabetic retinopathy was diagnosed based on fundus examination findings and was divided into proliferative and non-proliferative stages:

- non-proliferative diabetic retinopathy (NPDR): presence of microaneurysms, hemorrhages and hard exudates;

- proliferative diabetic retinopathy (PDR): presence of neovascularization.

\section{Laboratory investigations}

Blood was drawn for metabolic, biochemical and hematological parameters after a 12 hours overnight fasting and serum was used for measurement of the following: fasting plasma glucose (FPG) and fasting serum insulin [20]. Homeostasis Model Assessment 2 (HOMA2) calculator was used to estimate insulin resistance (\%S) (HOMA-IR) according to the updated computer based HOMA2 mode. Whole blood was mixed in EDTA tubes for glycated heamoglobin $\left(\mathrm{HbA}_{1 \mathrm{c}}\right)$ [20]. Lipid profile was measured including total serum cholesterol, high density lipoprotein cholesterol (HDL-C), low density lipoprotein cholesterol (LDL-C) and serum triglycerides [20]. Serum was collected in Eppendorf tubes and kept at $-80 \mathrm{C}$ till assay of leptin by using ELISA according to the manufacturer [21]. Urinary albumin/creatinine ratio (UACR) was measured in a random spot urine collection [22].

Serum creatinine was measured with calculation of eGFR for staging of diabetic kidney disease using CKD-EPI equation [23]. Diabetic kidney disease was diagnosed based on the presence of albuminuria (UACR $\geq 30 \mathrm{mg} / \mathrm{g}$ ) and/or reduced eGFR ( $<60 \mathrm{ml} / \mathrm{min} / 1.73 \mathrm{~m}^{2}$ ).

Statistical analysis of the data was done using IBM SPSS software package version 20.0. (Armonk, NY: IBM Corp). Qualitative data were described using number and percentage. The Kolmogorov-Smirnov test was used to verify the normality of distribution. Quantitative data were described using mean and standard deviation. Significance of the obtained results was judged at the $5 \%$ level. 
Table 1. Characteristics of participants $(n=120)$

\begin{tabular}{|c|c|c|}
\hline Measures & \multicolumn{2}{|c|}{ Mean \pm SD } \\
\hline Age (years) & \multicolumn{2}{|c|}{$53.03 \pm 7.65$} \\
\hline BMI $\left[\mathrm{kg} / \mathrm{m}^{2}\right]$ & \multicolumn{2}{|c|}{$32.11 \pm 3.26$} \\
\hline Waist circumference $[\mathrm{cm}]$ & \multicolumn{2}{|c|}{$110.4 \pm 10.21$} \\
\hline FPG [mg/dL] & \multicolumn{2}{|c|}{$139.4 \pm 46.88$} \\
\hline Insulin level $[\mu \mathrm{IU} / \mathrm{mL}]$ & \multicolumn{2}{|c|}{$13.37 \pm 10.67$} \\
\hline HOMA-IR & \multicolumn{2}{|c|}{$5.26 \pm 3.26$} \\
\hline $\mathrm{HbA}_{1 \mathrm{c}}(\%)$ & \multicolumn{2}{|c|}{$7.75 \pm 1.66$} \\
\hline Total cholesterol [mg/dL] & \multicolumn{2}{|c|}{$212.7 \pm 49.79$} \\
\hline Triglycerides [mg/dL] & \multicolumn{2}{|c|}{$175.0 \pm 77.59$} \\
\hline LDL-C [mg/dL] & \multicolumn{2}{|c|}{$107.7 \pm 33.65$} \\
\hline $\mathrm{HDL}-\mathrm{C}[\mathrm{mg} / \mathrm{dL}]$ & \multicolumn{2}{|c|}{$56.20 \pm 6.44$} \\
\hline eGFR $\left[\mathrm{ml} / \mathrm{min} / 1.73 \mathrm{~m}^{2}\right]$ & \multicolumn{2}{|c|}{$85.40 \pm 11.26$} \\
\hline UACR $[\mathrm{mg} / \mathrm{g}]$ & \multicolumn{2}{|c|}{$52.08 \pm 35.62$} \\
\hline Leptin [ng/ml] & \multicolumn{2}{|c|}{$20.26 \pm 7.74$} \\
\hline Sex & No. & $\%$ \\
\hline Male & 58 & 48.3 \\
\hline Female & 62 & 51.7 \\
\hline \multicolumn{3}{|l|}{ Duration of diabetes } \\
\hline$<5$ years & 48 & 40.0 \\
\hline Peripheral neuropathy & 26 & 21.7 \\
\hline Diabetic retinopathy & 28 & 23.3 \\
\hline Proliferative & 10 & 8.3 \\
\hline Non proliferative & 18 & 15.0 \\
\hline $\mathrm{UACR} \geq 30$ & 34 & 28.3 \\
\hline
\end{tabular}

CAD - coronary artery disease; $\mathrm{BMI}$ - body mass index; FPG — fasting plasma glucose; $\mathrm{HbA}_{1 \mathrm{C}}$ - hemoglobin $\mathrm{A}_{1} ; \mathrm{LDL}-\mathrm{C}$ - low density lipoprotein-cholesterol; HDL-C — high density lipoprotein-cholesterol; eGFR - estimated glomerular filtration rate; UACR — urinary albumin to creatinin ratio

The used tests were as follows:

- Mann-Whitney test: for abnormally distributed quantitative variables, to compare between two studied groups;

- Kruskal-Wallis test: for abnormally distributed quantitative variables, to compare between more than two studied groups;

- Spearman correlation coefficient was used to identify the correlation between the level of serum leptin and the other parameters in the studied subjects.

Statistical significance was set at $P$ value $\leq 0.05$.

\section{Results}

The present study was conducted among 120 participants with T2DM recruited from diabetes outpatient clinic of Alexandria Main University Hospital, Alexandria, Egypt. Participants' characteristics are mentioned in Table 1.
Table 2. Correlation between the level of serum leptin and the other parameters in the studied subjects

\begin{tabular}{lcc}
\hline & \multicolumn{2}{c}{ Patients } \\
\hline & $r_{\mathrm{s}}$ & $\mathbf{P}$ \\
Age (years) & 0.167 & 0.068 \\
Duration of DM (years) & 0.280 & $0.002^{*}$ \\
BMI [kg/m²] & 0.389 & $<0.001^{*}$ \\
Waist circumference [cm] & 0.413 & $<0.001^{*}$ \\
Systolic blood pressure [mm Hg] & 0.383 & $<0.001^{*}$ \\
Diastolic blood pressure [mm Hg] & 0.181 & $0.048^{*}$ \\
FPG [mg/dL] & 0.428 & $<0.001^{*}$ \\
Insulin $[\mu l \mathrm{~m} / \mathrm{mL}]$ & 0.247 & $0.006^{*}$ \\
HOMA-IR & 0.323 & $<0.001^{*}$ \\
HbA ${ }_{1 \mathrm{c}}(\%)$ & 0.282 & $0.002^{*}$ \\
Total cholesterol [mg/dL] & 0.363 & $<0.001^{*}$ \\
Triglycerides [mg/dL] & 0.338 & $<0.001^{*}$ \\
LDL-C [mg/dL] & 0.331 & $<0.001^{*}$ \\
HDL-C [mg/dL] & 0.086 & 0.350 \\
eGFR [ml/min/1.73 m²] & -0.273 & $0.003^{*}$ \\
UACR [mg/g] & 0.469 & $<0.001^{*}$ \\
\hline
\end{tabular}

$r_{s}$ - Spearman coefficient; * - statistically significant at $P \leq 0.05$ $\mathrm{BMI}$ - body mass index; FPG - fasting plasma glucose; $\mathrm{HbA}_{1 \mathrm{c}}$ - hemoglobin $\mathrm{A}_{1 \mathrm{c}}$; LDL-C — low density lipoprotein-cholesterol; HDL-C — high density lipoprotein-cholesterol; eGFR — estimated glomerular filtration rate; UACR - urinary albumin to creatinin ratio

Serum leptin level was significantly positively correlated with diabetes duration, BMI, WC, systolic and diastolic blood pressure, $\mathrm{FPG}, \mathrm{HbA}_{1 \mathrm{c}^{\prime}}$ serum insulin level, HOMA-IR, total cholesterol, triglycerides and LDL-C (Table 2).

\section{Correlation between serum leptin level} and microvascular complications of diabetes

There was highly statistically significant positive correlation between serum leptin and UACR (Table 2, Figure 1), peripheral neuropathy and retinopathy (Table 3) ( $P$ value $<0.001)$ and statistically significant negative correlation between serum leptin and eGFR (Table 2, Figure 2) (P value $<0.001)$

\section{Discussion}

Type 2 diabetes is a major health problem due to its high prevalence and the burden of its chronic complications [1]. Leptin is one of the adipokines incriminated in the pathogenesis of insulin resistance and T2DM. The present work was conducted to study the relation between serum leptin level and diabetic microvascular complications in a cohort of 120 participants with T2DM in Alexandria, Egypt. In the current study, serum leptin level was significantly positively correlated with 


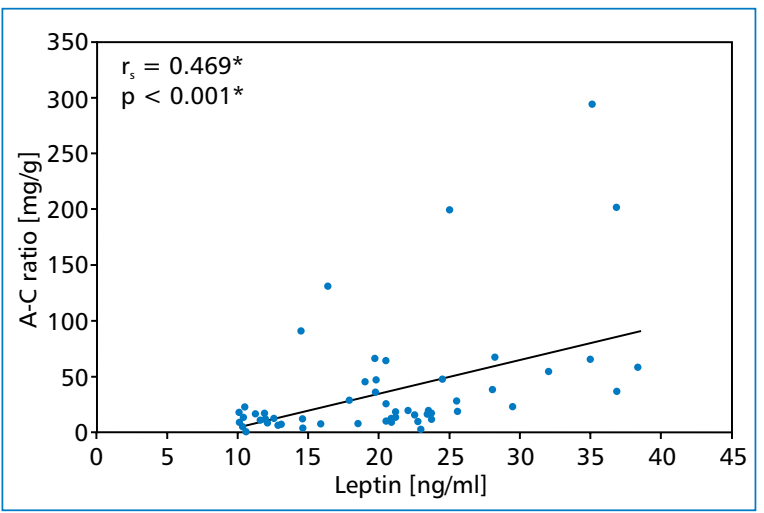

Figure 1. Correlation between leptin and UACR in studied subjects

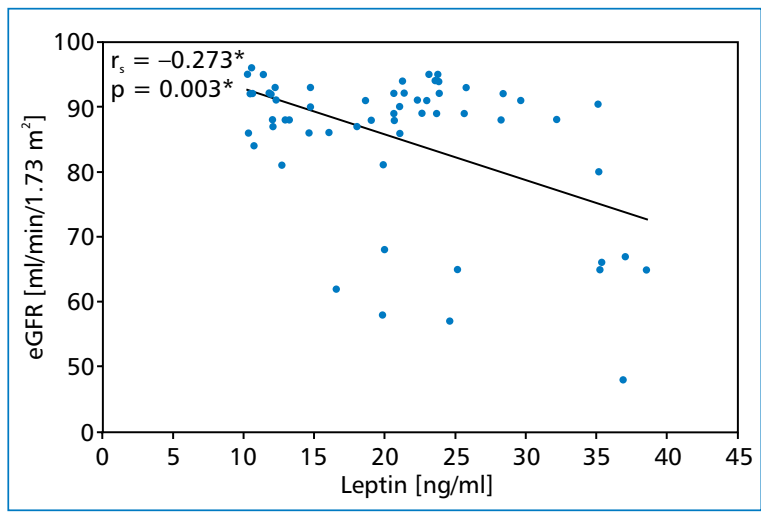

Figure 2. Correlation between leptin and eGFR in studied subjects

Table 3. Correlations between serum leptin level and peripheral neuropathy and retinopathy in the studied group

\begin{tabular}{|c|c|c|c|c|}
\hline & $\mathbf{N}$ & $\begin{array}{c}\text { Leptin } \\
\text { Mean } \pm \text { SD }\end{array}$ & Test of sig. & $\mathbf{P}$ \\
\hline \multicolumn{5}{|l|}{ Peripheral neuropathy } \\
\hline No & 94 & $18.10 \pm 6.14$ & $U=466.0^{*}$ & $<0.001^{*}$ \\
\hline Yes & 26 & $28.05 \pm 8.01$ & & \\
\hline \multicolumn{5}{|l|}{ Fundus examination } \\
\hline Normal & 92 & $18.14 \pm 6.20$ & $H=21.322^{*}$ & $<0.001^{*}$ \\
\hline Proliferafive & 10 & $29.26 \pm 7.13$ & & \\
\hline Non proliferafive & 18 & $26.09 \pm 8.86$ & & \\
\hline
\end{tabular}

$\mathrm{U}-$ Mann-Whitney test; $\mathrm{H}-\mathrm{H}$ for Kruskal-Wallis test; $\mathrm{p}-\mathrm{p}$ value for association between leptin and different parameters; * - statistically significant at $\mathrm{P} \leq 0.05$

diabetes duration, BMI, WC, systolic and diastolic blood pressure, FPG, $\mathrm{HbA}_{1 c^{\prime}}$ serum insulin level, HOMA-IR, total cholesterol, triglycerides and LDL-C. In agreement with the results of the present study, Cha et al. [24] found that plasma leptin level is positively correlated with BMI, fasting plasma glucose $\mathrm{HbA}_{1 \mathrm{c}}$ and total cholesterol values in patients with T2DM. Yassin et al. [25], who studied serum leptin level in patients with T2DM also found significant positive correlations between serum leptin and diabetes duration, cholesterol, triglycerides and LDL-C. Zulfania et al. [26] in concordance with the results of the present study found that serum leptin concentration was significantly correlated with BMI, FPG and $\mathrm{HbA}_{1 \mathrm{c}}$ in patients with T2DM.

Regarding the relation between serum leptin level and microvascular complications, the present study showed a significant positive correlation between serum leptin level and UACR, peripheral neuropathy and retinopathy and a significant negative correlation between serum leptin level and e-GFR. In concordance with the present study a meta-analysis by Rodríguez et al. [27] concluded that higher leptin levels were associated with microalbuminuria, macroalbuminuria and neuropathy, but in disagreement with the results of the present study, no association was found between serum leptin level and retinopathy. This difference may arise from the different patients' characteristics in studied cohorts. Cha et al. [24] showed similar results as they found a significant positive correlation between serum leptin level and urinary albumin excretion, and significant negative correlation with creatinine clearance. Yassin et al. [25] also showed a significant positive relation between serum leptin level and urinary albumin excretion and they concluded that serum leptin may be used as a marker of progression of diabetic kidney disease. On the other hand, Sari et al. [28], who studied the relation between serum leptin level and diabetic complications in patients with T2DM, found no significant difference between patients with and without diabetic nephropathy, retinopathy or neuropathy. Jung et al. [29], in concordance with the results of the present study, showed that serum leptin was significantly higher in patients with neuropathy than in patients without neuropathy. Uckaya et al. [30] studied the relation between serum leptin level and diabetic retinopathy and their results were similar to the 
results of the present study as they found a significantly higher leptin level in patients with proliferative and non-proliferative diabetic retinopathy than in patients without retinopathy.

\section{Conclusions}

From the results of the present study we concluded that serum leptin level is associated with microvascular complications in T2DM. This may be due to the proinflammatory potential of leptin and its involvement in subclinical inflammation and endothelial injury which are incriminated in the pathogenesis of microvascular complications. Further studies may declare the link between serum leptin level and progression of microvascular complications and the use of serum leptin level as a prognostic factor in patients with microvascular complications.

\section{Acknowledgement and funding}

This research was funded by Internal Medicine Department (Diabetes Unit) and Department of Chemical and Clinical Pathology, Faculty of Medicine, Alexandria University, Egypt.

\section{Conflict of interest}

The authors declare to have no conflict of interest.

\section{REFERENCES}

1. Classification and Diagnosis of Diabetes: Standards of Medical Care in Diabetes - 2020. Diabetes Care. 2019; 43(Suppl. 1): S14-S31, doi: 10.2337/dc20-s002.

2. Khalil SH, Megallaa $\mathrm{MH}$, Rohoma $\mathrm{KH}$, et al. Prevalence of type 2 diabetes mellitus in a sample of the adult population of Alexandria, Egypt. Diabetes Res Clin Pract. 2018; 144: 63-73, doi: 10.1016/j.diabres.2018.07.025, indexed in Pubmed: 30056190.

3. Lin Yi, Sun Z. Current views on type 2 diabetes. J Endocrinol. 2010; 204(1): 1-11, doi: 10.1677/JOE-09-0260, indexed in Pubmed: 19770178.

4. Kahn SE, Hull RL, Utzschneider KM. Mechanisms linking obesity to insulin resistance and type 2 diabetes. Nature. 2006; 444(7121): 840-846, doi: 10.1038/nature05482, indexed in Pubmed: 17167471

5. Abel ED, Peroni O, Kim JK, et al. Adipose-selective targeting of the GLUT4 gene impairs insulin action in muscle and liver. Nature. 2001; 409(6821): 729-733, doi: 10.1038/35055575, indexed in Pubmed: 11217863.

6. Kintscher U, Law RE. PPARgamma-mediated insulin sensitization: the importance of fat versus muscle. Am J Physiol Endocrinol Metab. 2005; 288(2): E287-E291, doi: 10.1152/ajpendo.00440.2004, indexed in Pubmed: 15637349.

7. Liu J, Fox CS, Hickson DA, et al. Impact of abdominal visceral and subcutaneous adipose tissue on cardiometabolic risk factors: the Jackson Heart Study. J Clin Endocrinol Metab. 2010; 95(12): 5419-5426, doi: 10.1210/jc.2010-1378, indexed in Pubmed: 20843952.

8. MacDougald OA, Hwang CS, Fan $\mathrm{H}$, et al. Regulated expression of the obese gene product (leptin) in white adipose tissue and 3T3-L1 adipocytes. Proc Natl Acad Sci U S A. 1995; 92(20): 9034-9037, doi: 10.1073/pnas.92.20.9034, indexed in Pubmed: 7568067.
9. Bado A, Levasseur S, Attoub $S$, et al. The stomach is a source of leptin. Nature. 1998; 394(6695): 790-793, doi: 10.1038/29547, indexed in Pubmed: 9723619.

10. Friedman JM, Halaas JL. Leptin and the regulation of body weight in mammals. Nature. 1998; 395(6704): 763-770, doi: 10.1038/27376, indexed in Pubmed: 9796811.

11. Moonishaa TM, Nanda SK, Shamraj M, et al. Evaluation of Leptin as a Marker of Insulin Resistance in Type 2 Diabetes Mellitus. Int J Appl Basic Med Res. 2017; 7(3): 176-180, doi: 10.4103/ijabmr. IJABMR_278_16, indexed in Pubmed: 28904917.

12. Guzik TJ, Marvar PJ, Czesnikiewicz-Guzik M, et al. Perivascular adipose tissue as a messenger of the brain-vessel axis: role in vascular inflammation and dysfunction. J Physiol Pharmacol. 2007; 58(4): 591-610, indexed in Pubmed: 18195475.

13. Bakker W, Eringa EC, Sipkema P, et al. Endothelial dysfunction and diabetes: roles of hyperglycemia, impaired insulin signaling and obesity. Cell Tissue Res. 2009; 335(1): 165-189, doi: 10.1007/ s00441-008-0685-6, indexed in Pubmed: 18941783

14. Tritos NA, Mantzoros CS. Leptin: its role in obesity and beyond. Diabetologia. 1997; 40(12): 1371-1379, doi: 10.1007/ s001250050838, indexed in Pubmed: 9447943.

15. Margetic S, Gazzola C, Pegg GG, et al. Leptin: a review of its peripheral actions and interactions. Int J Obes Relat Metab Disord. 2002; 26(11): 1407-1433, doi: 10.1038/sj.ijo.0802142, indexed in Pubmed: 12439643.

16. Paz-Filho G, Mastronardi $C$, Franco $C B$, et al. Leptin: molecular mechanisms, systemic pro-inflammatory effects, and clinical implications. Arq Bras Endocrinol Metabol. 2012; 56(9): 597-607, doi: 10.1590/s0004-27302012000900001, indexed in Pubmed: 23329181.

17. Khalil SA, Megallaa MH, Rohoma $\mathrm{KH}$, et al. Prevalence of chronic diabetic complications in newly diagnosed versus known type 2 diabetic subjects in a sample of Alexandria population, Egypt. Curr Diabetes Rev. 2019; 15(1): 74-83, doi: 10.2174/157339981 4666180125100917, indexed in Pubmed: 29366422.

18. Alberti KG, Zimmet P, Shaw J. Metabolic syndrome - a new world-wide definition. A Consensus Statement from the International Diabetes Federation. Diabet Med. 2006; 23(5): 469-480, doi: 10.1111/j.1464-5491.2006.01858.x, indexed in Pubmed: 16681555.

19. Pham H, Armstrong DG, Harvey $C$, et al. Screening techniques to identify people at high risk for diabetic foot ulceration: a prospective multicenter trial. Diabetes Care. 2000; 23(5): 606-611, doi: 10.2337/diacare.23.5.606, indexed in Pubmed: 10834417.

20. Sacks DB. Carbohydrates. In: Burtis CA, Ashwood ER, editors. Tietz textbook of clinical chemistry. 2nd ed. Philadelphia: WB Saunders. 1994: 935-949.

21. Ray Bio. Human leptin Elisa Kit https://www.raybiotech.com/ files/manual/ELISA/ELH-Leptin.pdf [accessed 18th January 2020].

22. Shaikh A, Seegmiller JC, Borland TM, et al. Comparison between immunoturbidimetry, size-exclusion chromatography, and LC-MS to quantify urinary albumin. Clin Chem. 2008; 54(9): 1504-1510, doi: 10.1373/clinchem.2008.107508, indexed in Pubmed: 18617580.

23. Stevens LA, Schmid CH, Zhang YL, et al. Development and validation of GFR-estimating equations using diabetes, transplant and weight. Nephrol Dial Transplant. 2010; 25(2): 449-457, doi: 10.1093/ndt/gfp510, indexed in Pubmed: 19793928.

24. Cha JJ, Hyun YY, Jee $\mathrm{YiH}$, et al. Plasma leptin concentrations are greater in type II diabetic patients and stimulate monocyte chemotactic peptide- 1 synthesis via the mitogen-activated protein kinase/extracellular signal-regulated kinase pathway. Kidney Res Clin Pract. 2012; 31(3): 177-185, doi: 10.1016/j. krcp.2012.06.004, indexed in Pubmed: 26894024.

25. Yassin MM, AbuMustafa AM, Yassin MM. Serum leptin in diabetic nephropathy male patients from Gaza Strip. Diabetes Metab Syndr. 2019; 13(2): 1245-1250, doi: 10.1016/j.dsx.2019.02.004, indexed in Pubmed: 31336472. 
26. Zulfania, Khan A, Ghaffar T, Kainat A, et al. Correlation between serum leptin level and body mass index (BMI) in patients with type 2 diabetes mellitus. J Pak Med Assoc. 2020; 70(1): 3-6, doi: 10.5455/JPMA.301135, indexed in Pubmed: 31954015.

27. Rodríguez AJ, Nunes Vd, Mastronardi CA, et al. Association between circulating adipocytokine concentrations and microvascular complications in patients with type 2 diabetes mellitus: A systematic review and meta-analysis of controlled cross-sectional studies. J Diabetes Complications. 2016; 30(2): 357-367, doi: 10.1016/j.jdiacomp.2015.11.004, indexed in Pubmed: 26684169 .
28. Sari R, Balci MK, Apaydin C. The relationship between plasma leptin levels and chronic complication in patients with type 2 diabetes mellitus. Metab Syndr Relat Disord. 2010; 8(6): 499-503, doi: 10.1089/met.2009.0127, indexed in Pubmed: 21121702.

29. Jung CH, Kim BY, Mok JO, et al. Association between serum adipocytokine levels and microangiopathies in patients with type 2 diabetes mellitus. J Diabetes Investig. 2014; 5(3): 333-339, doi: 10.1111/jdi.12144, indexed in Pubmed: 24843783.

30. Uckaya G, Ozata M, Bayraktar Z, et al. Is leptin associated with diabetic retinopathy? Diabetes Care. 2000; 23(3): 371-376, doi: 10.2337/diacare.23.3.371, indexed in Pubmed: 10868868. 